\title{
Comparison between the Thelliers' and Shaw's Palaeointensity Methods Using Basalts Less than 5 Million Years Old
}

\author{
W. E. Senanayake, M. W. McElhinny, and P. L. McFadden \\ Research School of Earth Sciences, Australian National University, \\ Canberra, Australia
}

(Received June 23, 1981; Revised February 13, 1982)

\begin{abstract}
We present 45 new determinations of the intensity of the geomagnetic field from basaltic rocks, less than $5 \mathrm{Ma}$ in age, at sites mainly in the southern hemisphere. For 43 samples both Thelliers' (modified by Coe) and Shaw's (modified by Kono) methods were used and in some cases repeat measurements were made on several specimens. The results using the two methods are in excellent agreement and show no systematic difference. The within-specimen and between-sample measurements at each site exhibit internal consistency that can be associated with standard errors in the palaeointensities of $10 \%$.

Very importantly the specimens for the determinations were individually selected using a new simple method based on low temperature susceptibility variation down to liquid nitrogen temperatures. Better than $90 \%$ success rate was achieved with such specimens in providing good palaeointensities using either method. We attribute the high success rate and the agreement between methods to the method of specimen selection.
\end{abstract}

\section{Introduction}

A basic assumption in palaeomagnetic studies has been that the geomagnetic field, when averaged over periods of $10^{4}$ to $10^{5}$ years, is that of a geocentric axial dipole (GAD). The GAD hypothesis has served as an excellent first order model, especially for the use of palaeomagnetic data in terms of continental drift (Irving, 1964; McElhinny, 1973). Detailed analyses of the data covering the past few million years have shown that there are second order effects which produce significant departures from the GAD hypothesis (Wilson, 1970, 1971, 1972; Wilson and McElhinny, 1974; Cox, 1975). MerRILl and MCELHINNy (1977) have shown that the time-averaged field is best represented by a series of zonal harmonics in a spherical harmonic expansion. Unfortunately the higher order terms have to be expressed in terms of ratios of quadrupole, octupole etc. to the main dipole term. One important result of the analysis of MERRILL and McELHINNY (1977) is that the ratio of the quadrupole to dipole term, $g_{2}{ }^{0} / g_{1}{ }^{0}$, was significantly different for the normal and reversed field when averaged over the past 5 million years. They were unable to show whether the quadrupole terms or dipole terms or both are different for the normal and reversed fields. The difference in the $g_{2}{ }^{0} / g_{1}{ }^{0}$ ratios is about $25 \%$ and this could mean in the limit that the quadrupole fields differ by $25 \%$ between its normal and reversed state with the dipole field remaining unchanged. To decide this point a suitable number of 
estimates of the normal and reversed dipole field strength, covering the past 5 million years, must be available.

There are recorded over 100 palaeointensities determined on rocks of such age but all of these are from rocks of the northern hemisphere. In this work we have attempted to correct the imbalance in data distribution by obtaining the first palaeointensities from the southern hemisphere on rocks less than 5 million years old but greater than 50,000 years old, making use of the collections of young basalts available at the Australian National University from previous investigations related to studies of the geomagnetic polarity time scale.

The classical palaeointensity method of THELLIER and THELLIER (1959) is very time consuming and much effort has been devoted to devising alternative procedures which reduce the amount of laboratory work involved. SHAw's (1974) method has become increasingly attractive because it appears to have overcome all the objections to many of the other methods that have been proposed. The advantage in Shaw's method is that an additional consistency check is undertaken to ensure no mineralogical change affecting the coercive force spectrum has occurred on heating. However, lingering doubts may still persist because some experiments have demonstrated that the comparison of alternating field demagnetization spectra before and after heating does not necessarily provide correct palaeointensities (COE and GROMME, 1973). In this work we have attempted to investigate the viability of Shaw's technique by comparing results on parallel specimens using the Thelliers' method. Specimens were preselected for palaeointensity work using the new and simple method proposed by SenanayaKe and McElhinny (1981).

\section{Sample Selection}

SenAnAyake and McElhinny (1981) have shown that for typical basalts the magnetic susceptibility from room temperature down to liquid nitrogen temperature can be used to identify the grain size and magnetite-titanomagnetite composition that predominates in any sample. The variation in susceptibility almost always falls into one of three types. Type 1 basalts show a gradual decrease from their room temperature susceptibility to an average of 0.27 times this value at liquid nitrogen temperatures. These samples are dominated by multidomain titanomagnetites and are characterized by low coercive force and low Curie temperature. Type 2 basalts show a susceptibility increase to an average of 1.26 times the room temperature value at liquid nitrogen temperatures. They consist mainly of titanomagnetite grains with exsolved ilmenite lamellae and are characterized by high resistance to alternating field demagnetization and by increased Curie temperatures. The observed low temperature susceptibility increase is due to stress effects on subdivided regions created by the crowded ilmenite lamellae. Type 3 samples show an increase in susceptibility to a peak of 1.24 times the room temperature value around $-140^{\circ} \mathrm{C}$ followed by a decrease to 1.04 times the room temperature value at liquid nitrogen temperatures. These are predominantly multidomain magnetite or magnetite-rich titanomagnetites. They have higher Curie temperatures than type 1 and coercivities intermediate between types 1 and 2 .

SENANAYAKE and MCELHINNY (1981) have pointed out that the type 2 basalts are 
those with the most desirable characteristics for palaeomagnetic studies. Furthermore, because their oxidation state is much more advanced than that of types 1 and 3, they should be particularly useful for palaeointensity studies. The laboratory heatings necessary in palaeointensity studies would likely affect these samples least. SENANAYAKE and MCELHinNy (1981) therefore suggested that samples suitable for palaeointensity studies could be preselected simply by looking at their low temperature susceptibility variation.

Collections of basalts from Mauritius (McDougall and Chamalaun, 1969), Reunion (Chamalaun, 1968), Norfolk Island (AzIZ-UR-Rahman and McDougall, 1973), the Society Islands (DunCAN, 1975), the Newer Volcanics of Victoria (AzIZ-URRAHMAN, 1971) and Iceland (WATKINs et al., 1975, 1977) whose ages were known to be less than $5 \mathrm{Ma}$ were systematically investigated using the low temperature susceptibility classification outlined above. Of 716 specimens investigated in this way, 234 fell into the type 2 classification, and 149 of these from 45 sites were used for palaeointensity determinations.

\section{Procedure}

The classical method of palaeointensity determination is that due to the Thelliers (Thellier and Thellier, 1959). In this method the natural remanent magnetization (NRM) destroyed between successive temperatures $\left(T_{1}, T_{2}\right.$, etc.) is compared with the thermoremanent magnetization (TRM) acquired in the same interval. The most common approach in use currently is the Modified Thelliers' Method of COE (1967). A series of double stepwise heatings are used. In the first the partial NRM (PNRM) between temperatures $T_{1}$ and $T_{2}$ is removed by cooling in zero field and in the second a partial TRM (PTRM) is acquired over the same interval by cooling in some laboratory field $F_{l}$. Because of the law of additivity of PTRM, the ratio PNRM/PTRM should be constant over each interval. If alteration occurs on heating to higher temperatures this may be diagnosed by a change in the ratio after several heatings have been made. There is general agreement that the Thelliers' technique is the most reliable available. It suffers from the disadvantage that a large number of heatings (20 to 30 typically) are required for each determination. Even then it is not guaranteed that a result will be obtained.

To overcome the drawbacks of the Thelliers' method attempts have been made to use alternating field demagnetization methods that are very much quicker. Here the specimen is heated once to the Curie temperature, cooled in the laboratory field $F_{l}$, and the alternating field demagnetization spectra of NRM and TRM compared (SMITH, 1967). If the ratio of PNRM/PTRM between successive alternating fields $H_{1}$ and $H_{2}$, say, is constant then it is argued that the coercivity spectrum is unaltered and that no alterations have occurred on heating. The ancient field strength $F_{a}$ is then related to the $\operatorname{PNRM}\left(J_{n}\right)$ and PTRM $\left(J_{t}\right)$ in the Thelliers' or the alternating field methods by the equation 
or

$$
\left.\begin{array}{c}
\frac{J_{n}\left(T_{1}, T_{2}\right)}{J_{t}\left(T_{1}, T_{2}\right)}=\frac{F_{a}}{F_{l}} \\
\frac{J_{n}\left(H_{1}, H_{2}\right)}{J_{t}\left(H_{1}, H_{2}\right)}=\frac{F_{a}}{F_{l}}
\end{array}\right\}
$$

However, it is not clear that the change in coercivity spectrum of NRM and TRM is a very sensitive indicator of chemical alterations. SHAw (1974) therefore suggested that one can demonstrate the absence of alteration or identify the portion of coercivity spectrum not affected by the alteration, by comparing the alternating field demagnetization spectrum of anhysteretic remanent magnetization (ARM) before and after heating. A plot of ARM1 (before heating) versus ARM2 (after heating) for successive demagnetization fields will produce a straight line of unit slope if there has been no alteration. It is already well known that ARM has characteristics similar to TRM, including the observation that ARM is proportional to the magnitude of the steady field applied and that a law of additivity of partial ARM applies (PATtON and Fitch, 1962).

Kono (1978) has made an investigation of the reliability of palaeointensity methods using alternating field demagnetization and ARM techniques. Using volcanic rocks whose TRM was acquired in known fields, he compared the results obtained by the Thelliers' and by Shaw's method. He concluded that samples gave reliable results when the demagnetization spectra of ARM induced before and after heating were identical (the plot of ARM1 versus ARM2 gave unit slope). However, even if the slope of ARM1 versus ARM2 differed from unity, assuming the changes in NRM demagnetization spectrum matched the changes in ARM demagnetization spectrum, then a correction could be applied to Shaw's method to give a reliable result.

Suppose that the slope of the NRM-TRM plot in Shaw's method is $m_{1}$ and the slope of the corresponding ARM1-ARM2 plot is $m_{2}$, then following KonO (1978), the palaeointensity $F_{a}$ is given by

$$
F_{a}=\frac{m_{1}}{m_{2}} F_{l}
$$

Kono (1978) subdivided the response of samples to demagnetization of ARM as follows. Class 1 samples are those for thich the ARM1-ARM2 relation is linear with gradient unity, Class 2 are those for which the ARM1-ARM2 relation is linear but the gradient is not unity, and Class 3 are those for thich the ARM1-ARM2 relation is non-linear. Class 1 samples are those accepted by SHAW (1974) in his original method. However KonO (1978) has shown that Class 2 samples also given reliable results if the correction term given by Eq. (2) is applied. We shall refer to this as the Modified Shaw's method.

In this paper we shall compare the results obtained by the Modified Thelliers' method with the Modified Shaw's method. For this purpose 63 specimens were analysed by the Modified Shaw's method and 86 by the Modified Thelliers' method. 


\section{Palaeointensity Results}

Figures 1 and 2 provide comparisons between the Modified Thelliers' method and Modified Shaw's method for adjacent specimens in a variety of cases. In Fig. 1 the ARM1-ARM2 slopes are not significantly different from unity at the $95 \%$ confidence
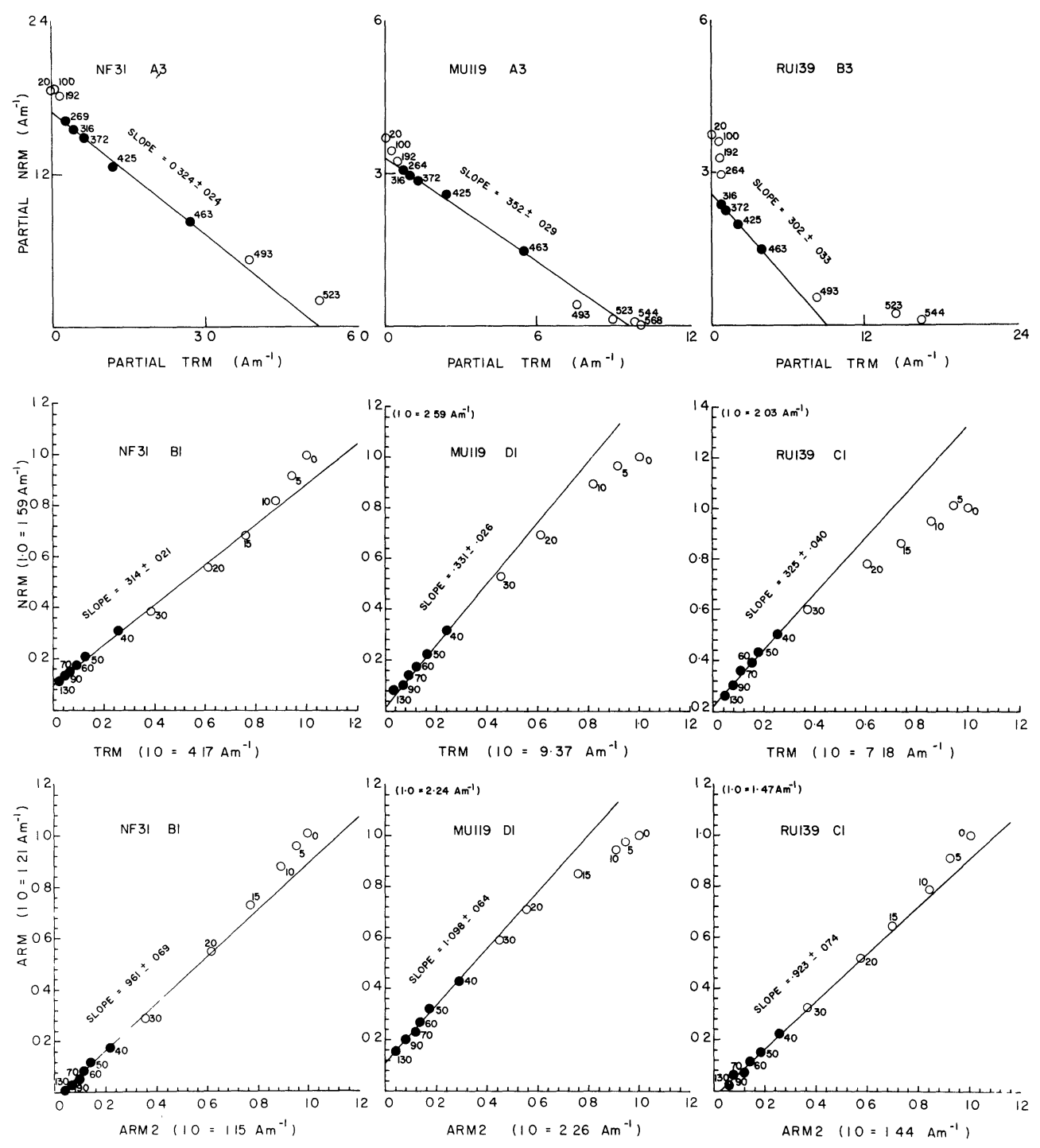

Fig. 1. Comparison of results from the Modified Thelliers' method with those from the Modified Shaw method where ARM1-ARM2 slopes are not significantly different from unity at the $95 \%$ confidence level. Linear least-squares analysis was carried out using the solid data points only to give the indicated slope. Errors quoted are standard errors. Temperature $\left({ }^{\circ} \mathrm{C}\right)$ are indicated at points on the PNRM-PTRM diagrams (top row) and alternating fields (mT) on the NRMTRM (second row) and ARM1-ARM2 (third row) diagrams. 
level. These samples would all classify as Class 1 of Kono (1978) or 'ideal' samples following SHAw's (1974) original method. In Fig. 2 two results are shown in which the ARM1-ARM2 slopes are significantly greater than and less than unity respectively. These are the Class 2 samples of Kono (1978). Also two results are illustrated in which neither the Modified Thelliers' nor the Modified Shaw's method give reliable results.
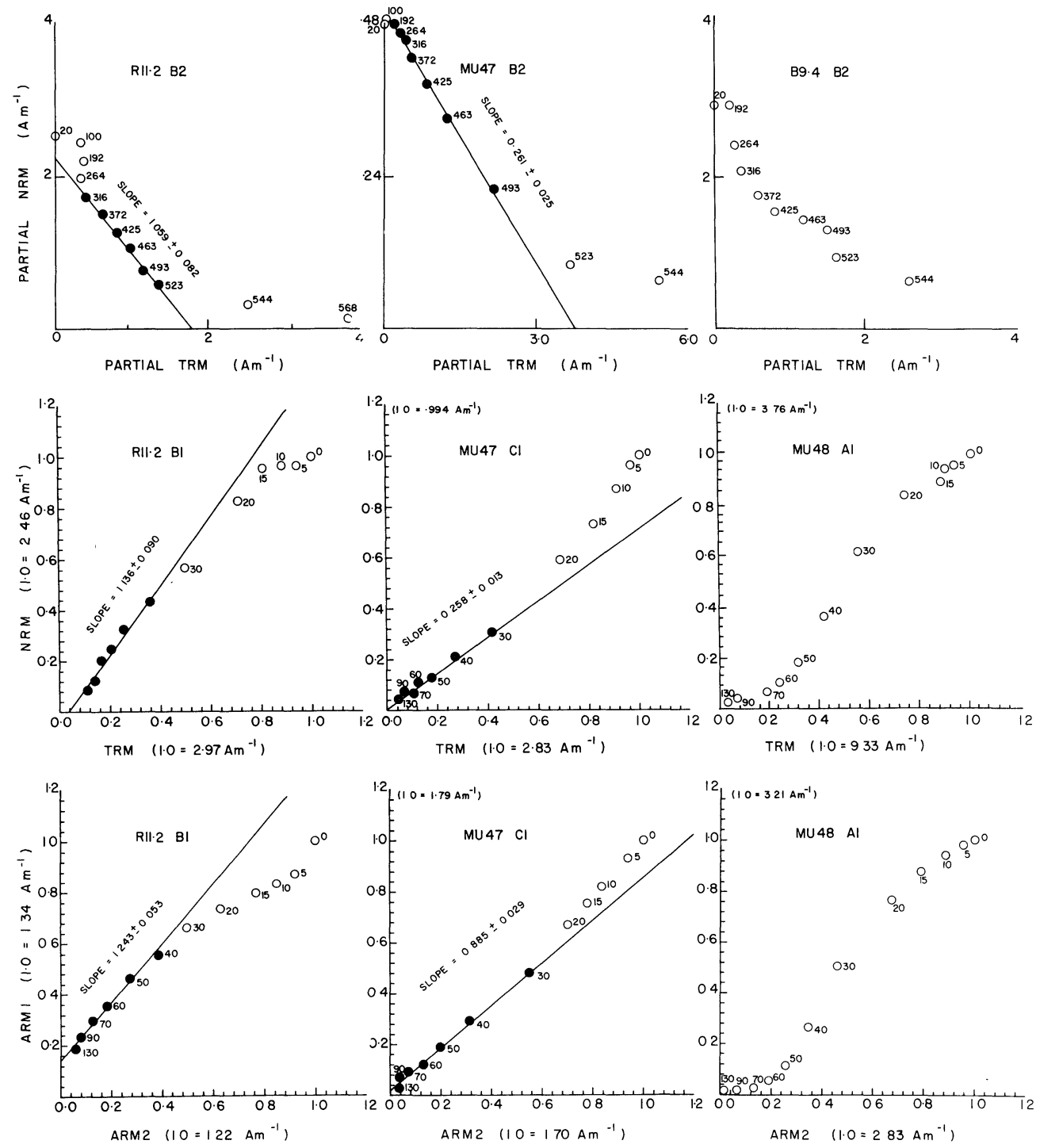

Fig. 2. Comparison of results from the Modified Thelliers' method with those from the Modified Shaw method where ARM1-ARM2 slopes differ significantly from unit, or where no results could be obtained from the data. See Fig. 1 for further details. 


\subsection{The Thelliers' method}

The three PNRM-PTRM diagrams in the top row of each of Figs. 1 and 2 illustrate typical results obtained using the Modified Thelliers' method. The criteria of CoE et al. (1978) for determining the linear segments of the PNRM-PTRM diagrams were used. The straight line segment should have a minimum of four points with no anomalous points within the segment being eliminated. Segments with systematic curvature should be avoided and the length of the segment should always be at least $15 \%$ of the total extrapolated NRM. In the rocks used in this study this segment was invariably at least $50 \%$ of the total extrapolated NRM. Typically the straight line segments lay between $200^{\circ} \mathrm{C}$ and $450^{\circ} \mathrm{C}$, although occasionally this was extended to $150^{\circ} \mathrm{C}$ and $500^{\circ} \mathrm{C}$ at the low and high temperature ends respectively. Because these rocks are much older than Holocene there were always secondary components, or decay of NRM present that made the data at temperatures $<150^{\circ} \mathrm{C}$ or $200^{\circ} \mathrm{C}$ unusable (see Figs. 1 and 2).

Both CoE et al. (1978) and ChAmpion (1980) in studies of Holocene basalts have stressed the usefulness in using the low temperature portions of the data $\left(\leq 300^{\circ} \mathrm{C}\right)$ to prevent oxidation effects occurring. The presence of secondary components in older rocks, such as in this study, would have limited the useful temperature range to a very narrow interval if their procedure had been followed. However, we believe that our preselection criteria, in which the more oxidized samples are selected, have resulted in providing samples with extended temperature ranges before the onset of further oxidation occurs. Of 86 specimens investigated, only seven had to be rejected because there was no definable linear segment on the PNRM-PTRM diagram (see example in Fig. 2). The results from the 79 successful specimens are listed in Table 1. In all cases a laboratory field of $59 \mu \mathrm{T}$ was used, and linear least-squares fits to the PNRM-PTRM data were determined. The errors quoted in Figs. 1 and 2 and in Table 1 are standard errors.

\subsection{The Modified Shaw method}

The results of the Shaw technique for specimens adjacent to those already used for the Thelliers' technique are shown in Figs. 1 and 2 beneath the Thellier PNRM-PTRM diagrams. All TRMs were induced in a field of $59 \mu \mathrm{T}$. The median demagnetization field of the NRM under alternating field demagnetization was fairly high for all specimens $(\geq 20 \mathrm{mT})$ and the remanence direction was always very stable even at fields greater than $100 \mathrm{mT}$. In most specimens NRM directions were consistent over a wide range of peak alternating fields (usually $20 \leq H \leq 150$ or $160 \mathrm{mT}$ ). At low fields small secondary magnetizations were removed. These are characteristics typically to be expected from type 2 basalts (SENANAYAKe and McElHinny, 1981).

The ARMs before and after heating (ARM1 and ARM2 respectively) were induced in a steady field of $59 \mu \mathrm{T}$ and a peak alternating field of $200 \mathrm{mT}$ gradually reduced to zero. Correponding NRM-TRM and ARM1-ARM2 plots are illustrated in Figs. 1 and 2. For virtually all specimens investigated the ARM1-ARM2 plots were linear in the range $30-40 \leq H \leq 130 \mathrm{mT}$. Changes in the coercive force spectrum in the low alternating field range $(<30 \mathrm{mT})$ may well relate to the oxidation of particular grains during heating. The bulk of the remanence residing in the higher coercivity range probably relates to that residing in grains with subdividing ilmenite lamellae as are the characteristics of type 2 


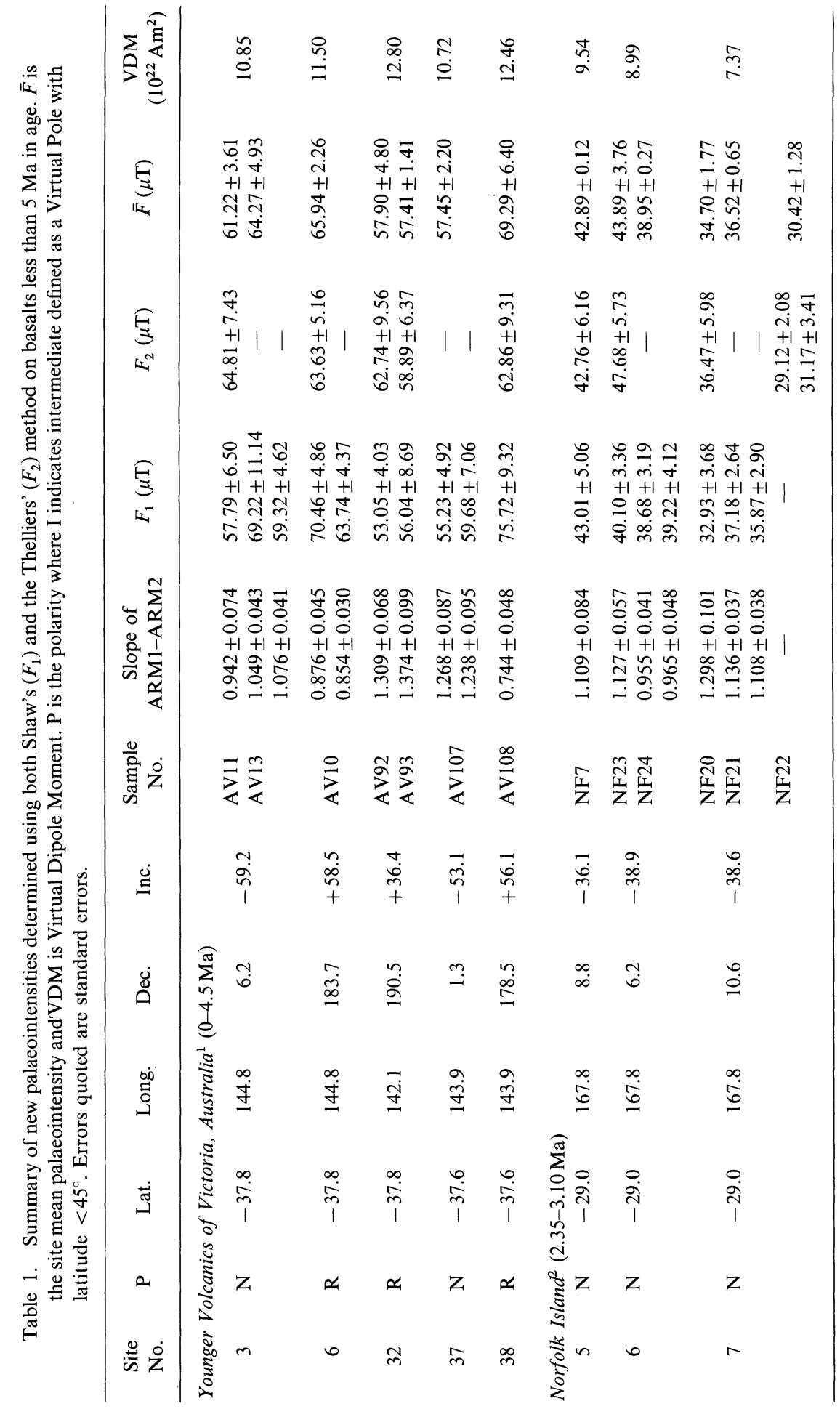


Comparisons between the Thellier's and Shaw's Palaeointensity Methods

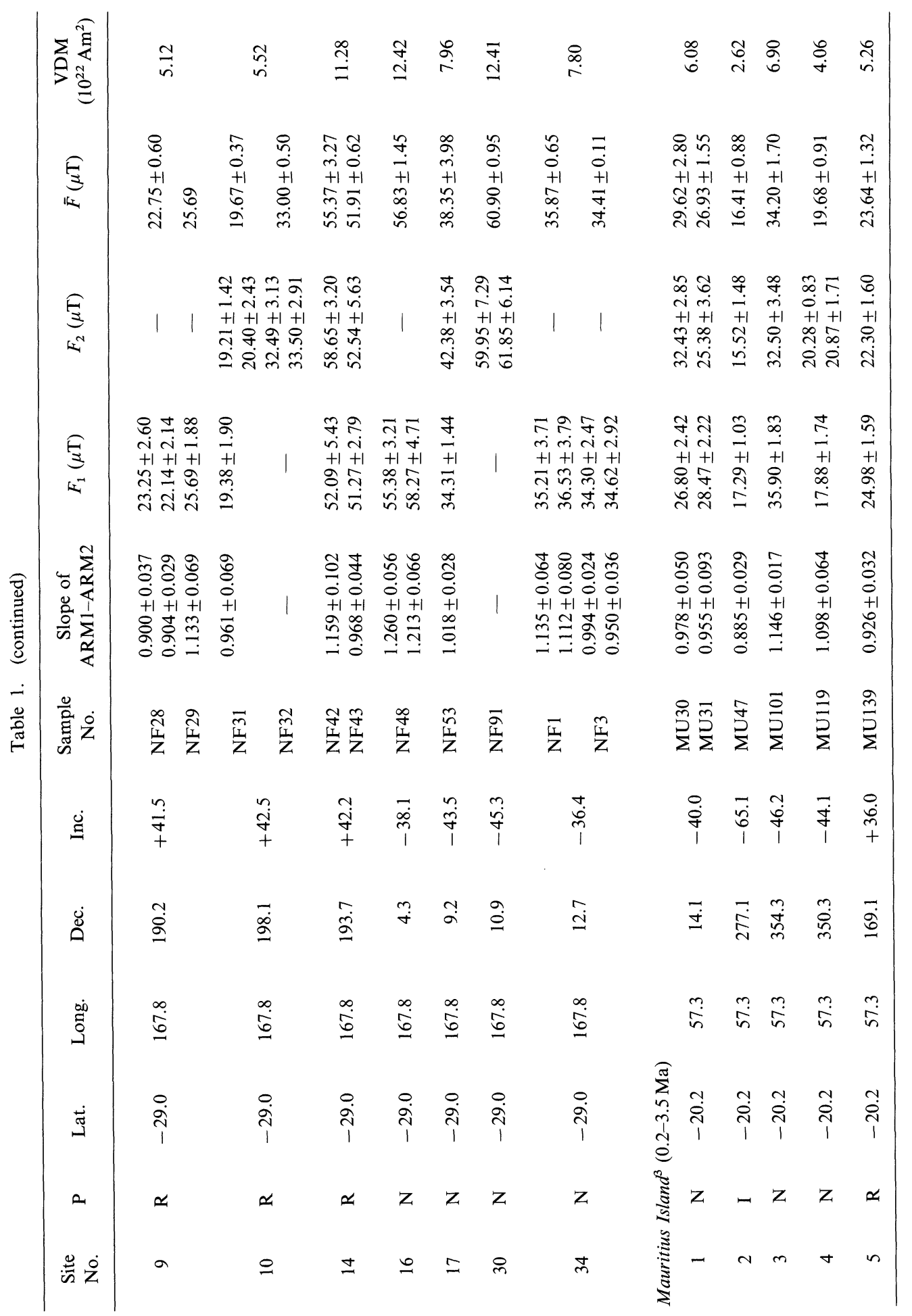




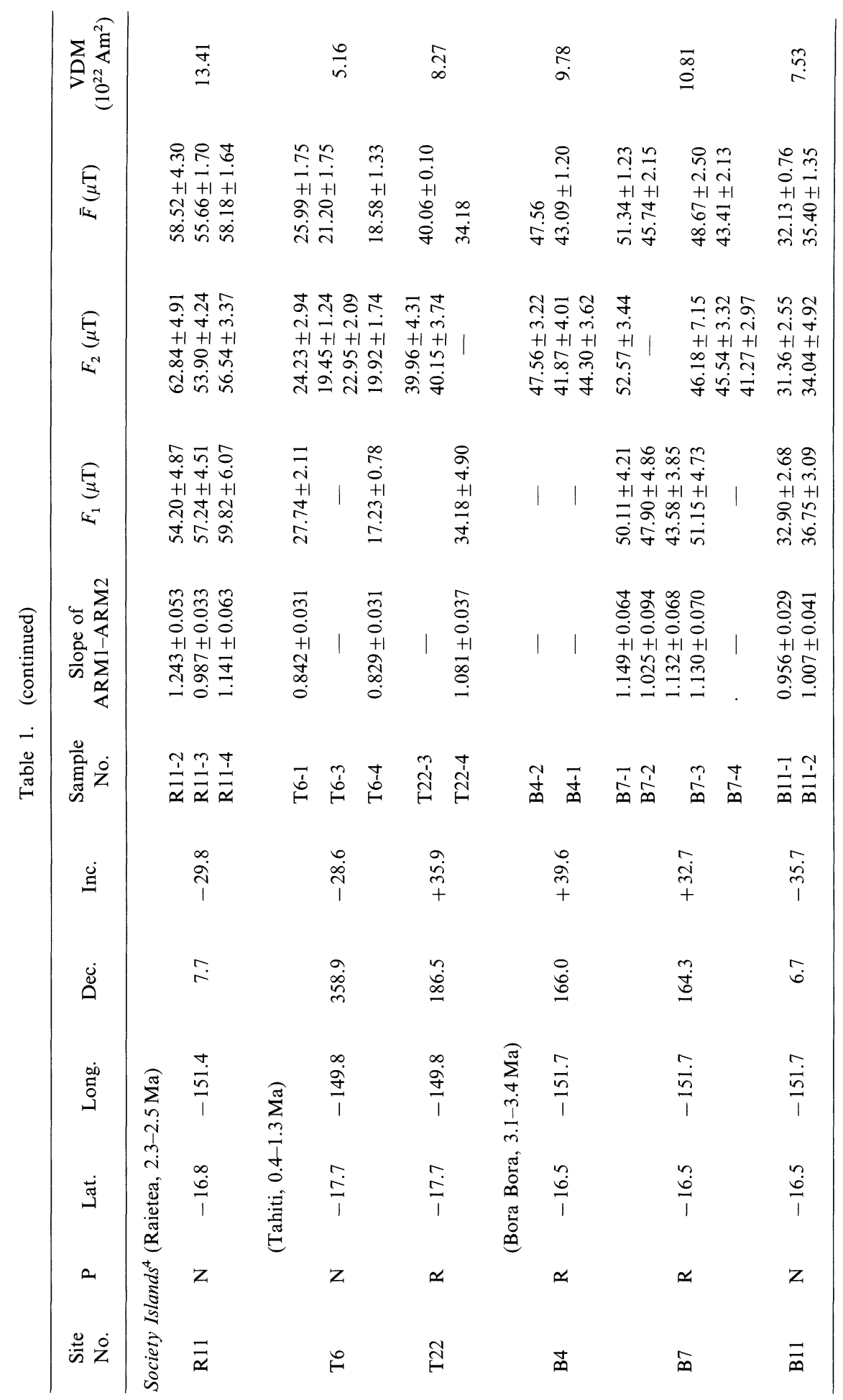


Comparisons between the Thellier's and Shaw's Palaeointensity Methods

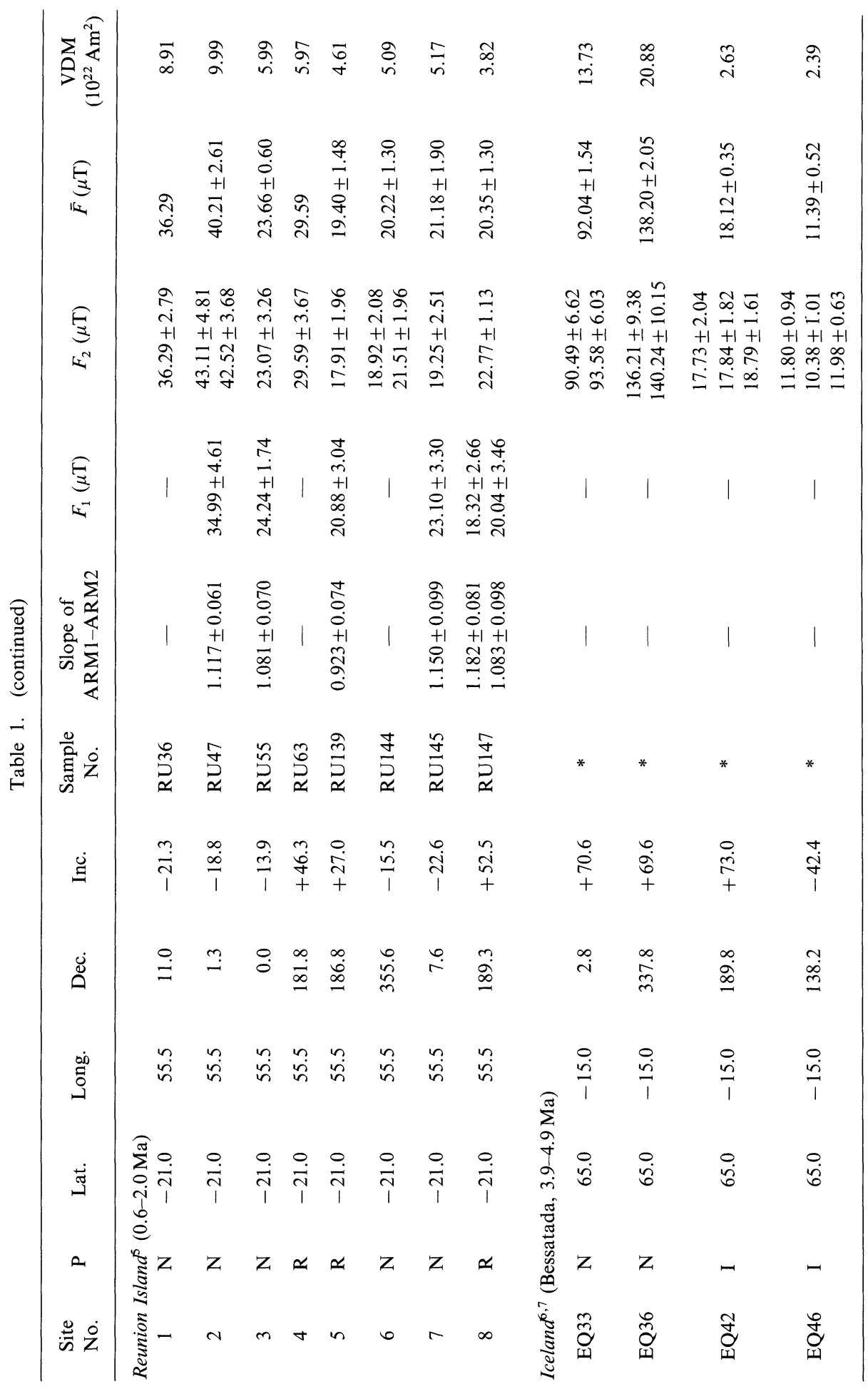




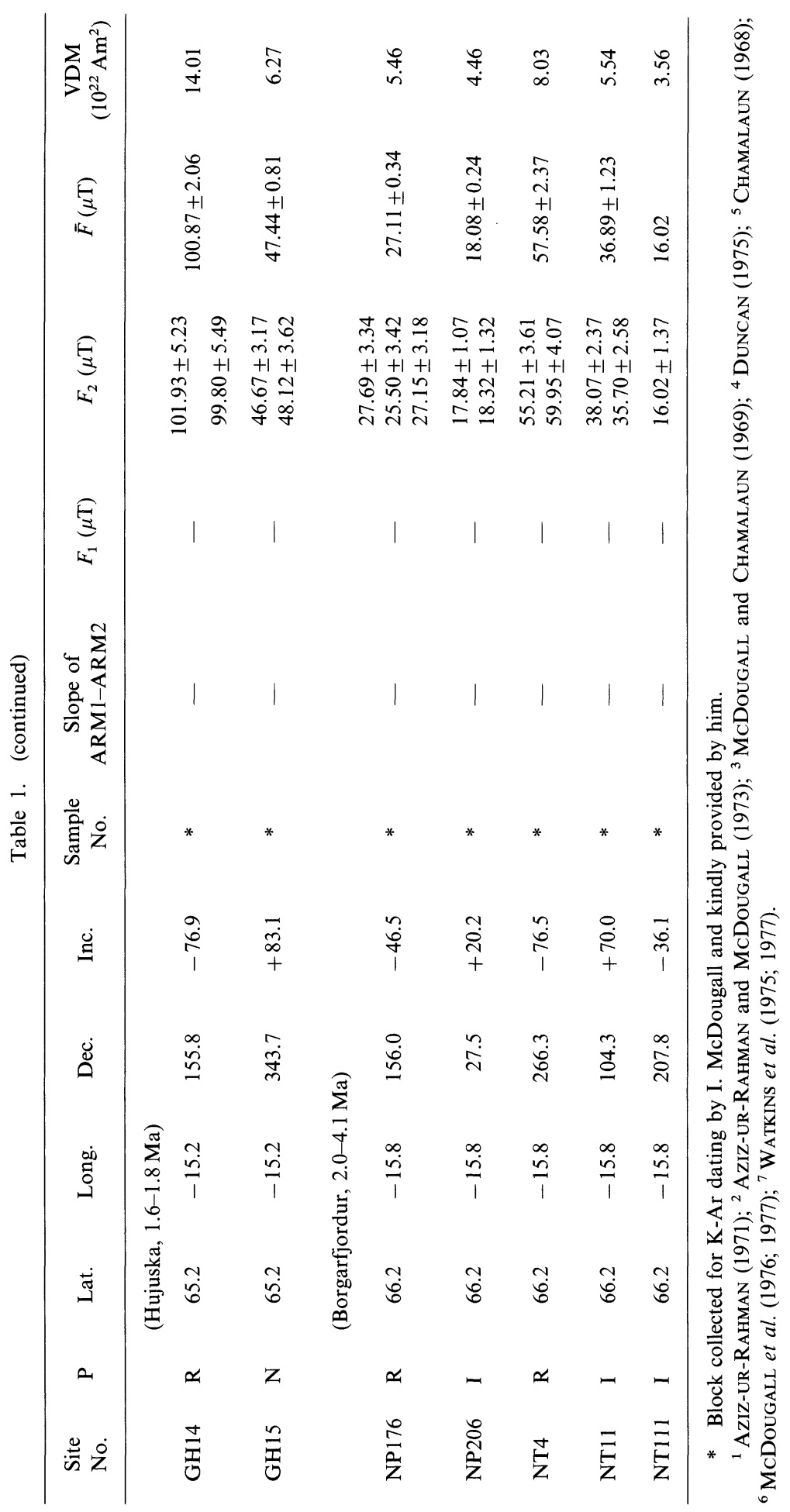


basalts.

Linear least-squares fits to the NRM-TRM and ARM1-ARM2 data were determined. The linear portion of the NRM-TRM diagram was required to cover the same range of alternating fields as that of the ARM1-ARM2 diagram. The criteria set out by COE et al. (1978) for determining the linear segments of PNRM-PTRM diagrams from the Thelliers' method were again applied except that here the length of the segment should be at least $15 \%$ of the length of the distance between the zero field point and the $130 \mathrm{mT}$ point. Figure 1 illustrates three cases where the slopes of the ARM1-ARM2 diagrams are not significantly greater than unity at the $95 \%$ confidence level. Figure 2 illustrates cases where the slopes are significantly different from unity or where no result could be determined.

The results are listed in Table 1 where the errors quoted are the standard errors in all cases. There was excellent agreement between the Modified Shaw's method and the Thelliers' method in virtually all cases. Most observed ARM1-ARM2 slopes lay within the range 0.7 to 1.4 . In two cases values of 2.13 and 1.83 were observed and there was no agreement with the corresponding Thelliers' result. We conclude that the Modified Shaw's method can be used if ARM1-ARM2 slopes lie in the range 0.7-1.4. Overall 6 of the 63 sets of data were rejected because there was no linear segment of the ARM1ARM2 plot or because the slope $m_{2}$ lay outside the acceptable range defined above. At the $95 \%$ confidence level 23 of the 43 samples produced values of $m_{2}$ not significantly different from unity. Of the remaining 20 samples, 8 had values of $m_{2}$ significantly less than unity and 12 had values significantly greater than unity.

\section{Comparison of the Thelliers' and Shaw's Methods}

All results listed in Table 1 have been converted to Virtual Dipole Moments (VDM) following SMITH (1967). VDM is defined as the equivalent geocentric dipole moment which would have produced the measured intensity, $F_{a}$, and inclination, $I$, hence

$$
\operatorname{VDM}=\frac{2 \pi R^{2} F_{a}}{\mu_{0}}\left(1+3 \cos ^{2} I\right)
$$

where $\mu_{0}$ is the permeability of free space and $R$ is the radius of the earth. The advantage of using the VDM is that data from different latitudes may be compared, and that no scatter is introduced into the distribution of VDMs as a result of dipole wobble.

There are results from 45 sites and 29 of these have separate determinations made by the Modified Thelliers' method and the Modified Shaw's method. The high success rate of Shaw's method $(90 \%)$ and for Thelliers' method $(92 \%)$ is attributed to the preselection of samples according to their low temperature susceptibility characteristics. Because the general reliability of the Modified Shaw's method could be in doubt, in spite of the exhaustive experiments of Kono (1978), we shall make a comparison of the two methods carried out in this paper.

Figure 3 shows the VDM difference determined by the two methods expressed as a percentage of the Thelliers' value for each sample. The difference between the methods is spread symmetrically about zero and furthermore the differences appear no different in 


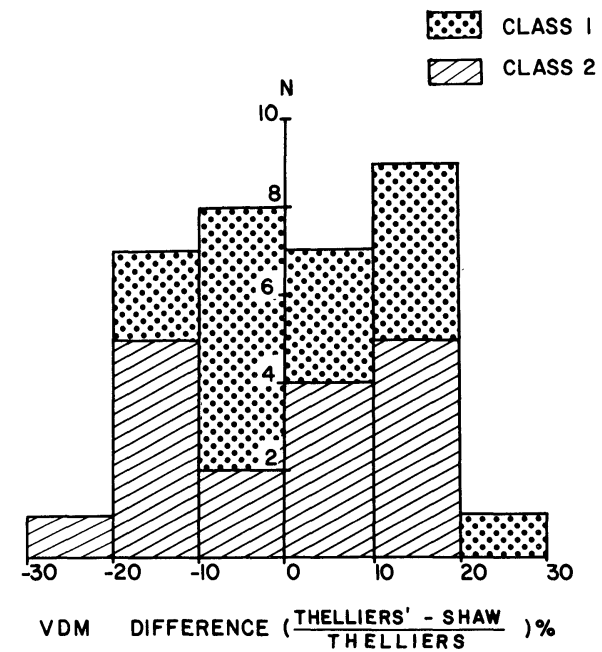

Fig. 3. Comparison of differences between VDMs determined by the Modified Thelliers' and Modified Shaw methods for Class 1 and Class 2 type samples of Kono (1978).

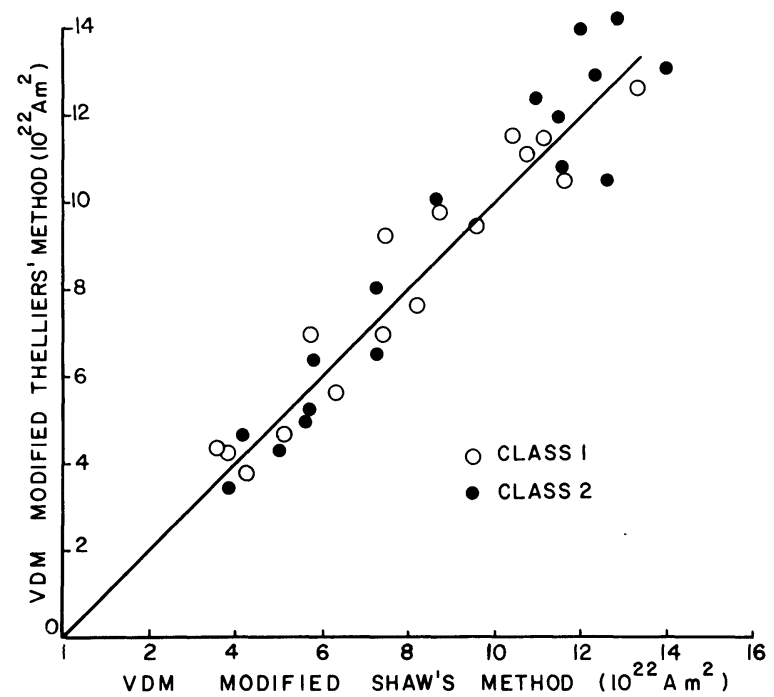

Fig. 4. Comparison of VDMs determined by the Modified Thelliers' and Modified Shaw methods for the Class 1 and Class 2 type samples of Kono (1978). The line is that to be expected for perfect agreement between the methods.

frequency if either Class 1 or Class 2 type Modified Shaw results are used. Also there is no significant trend to high or low values if high or low VDMs are found as illustrated in Fig. 4. A plot of VDMs determined by the Thelliers' method versus those by the Modified Shaw's method is equally scattered about the $45^{\circ}$ line.

The use of the ARM correction factor for Class 2 samples may also produce possible 


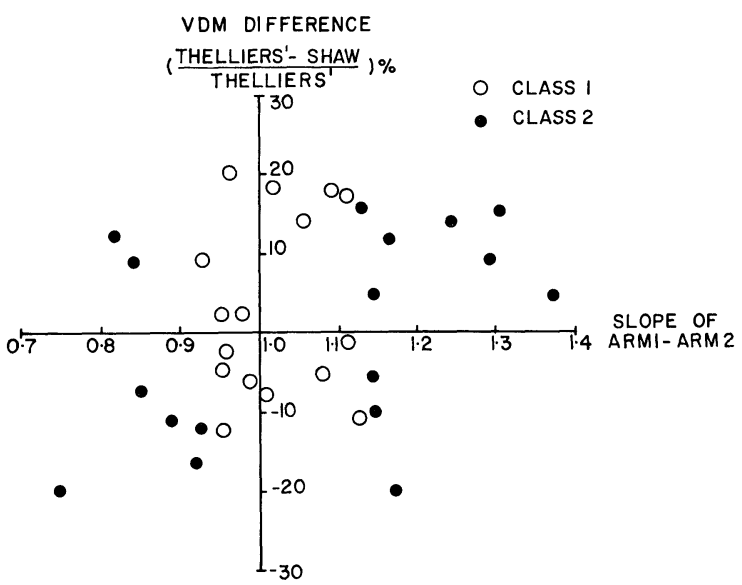

Fig. 5. Comparison of the differences between VDMs determined by the Modified Thelliers' and Modified Shaw methods as a function of the ARM1-ARM2 slope in the Modified Shaw method. The Class 1 and Class 2 type samples of Kono (1978) are indicated.

bias towards high or low values. To test this Fig. 5 shows a plot of the percentage difference between the results as a function of the slope of the ARM1-ARM2 plot. The scatter in the differences for the Class 2 samples is no difference from that of the Class 1 samples. Therefore there appear to be no systematic differences between the Thelliers' method and the modified Shaw's method when using our method of sample preselection. A detailed analysis of the errors follow in the next section.

\subsection{Within specimen errors}

The overall errors expressed as estimated standard deviation of individual measurements are given in Table 1 for each determination. A histogram of these errors, from both methods, is plotted in Fig. 6a and it may be seen that the distributions are similar. Since these errors have been determined from least-squares linear fits it is to be expected that the estimated variances will be chi-square distributed, provided the number of points used in each fit is the same. In fact, the number of points per fit varies from 4 to 7 (see inset in Fig. 6 b) so the distribution of all the estimated variances cannot be truly chi-squared but should still approximate a chi-square distribution. For the Modified Thelliers' method the error in the slope of the least-squares line on the PNRM-PTRM plot essentially determines the overall error, but for the Modified Shaw's method the errors in the slopes of both the NRM-TRM and ARM1-ARM2 plots contribute to the overall error. Hence, even if the mean percentage error of the two methods is the same, it is to be expected that the dispersion of the observed errors will be greater for the Modified Shaw's method than for the Modified Thelliers' method.

The best fit chi-square distribution to the 57 estimated variances (see Fig. 6b) from the Modified Shaw's method has 4 degrees of freedom (d.o.f.) with a mean estimated variance of 103.1 (mean estimated standard deviation of $10.2 \%$ ). The acceptability of this fit may be tested by the usual chi-square goodness of fit test. In performing this test 8 cells 

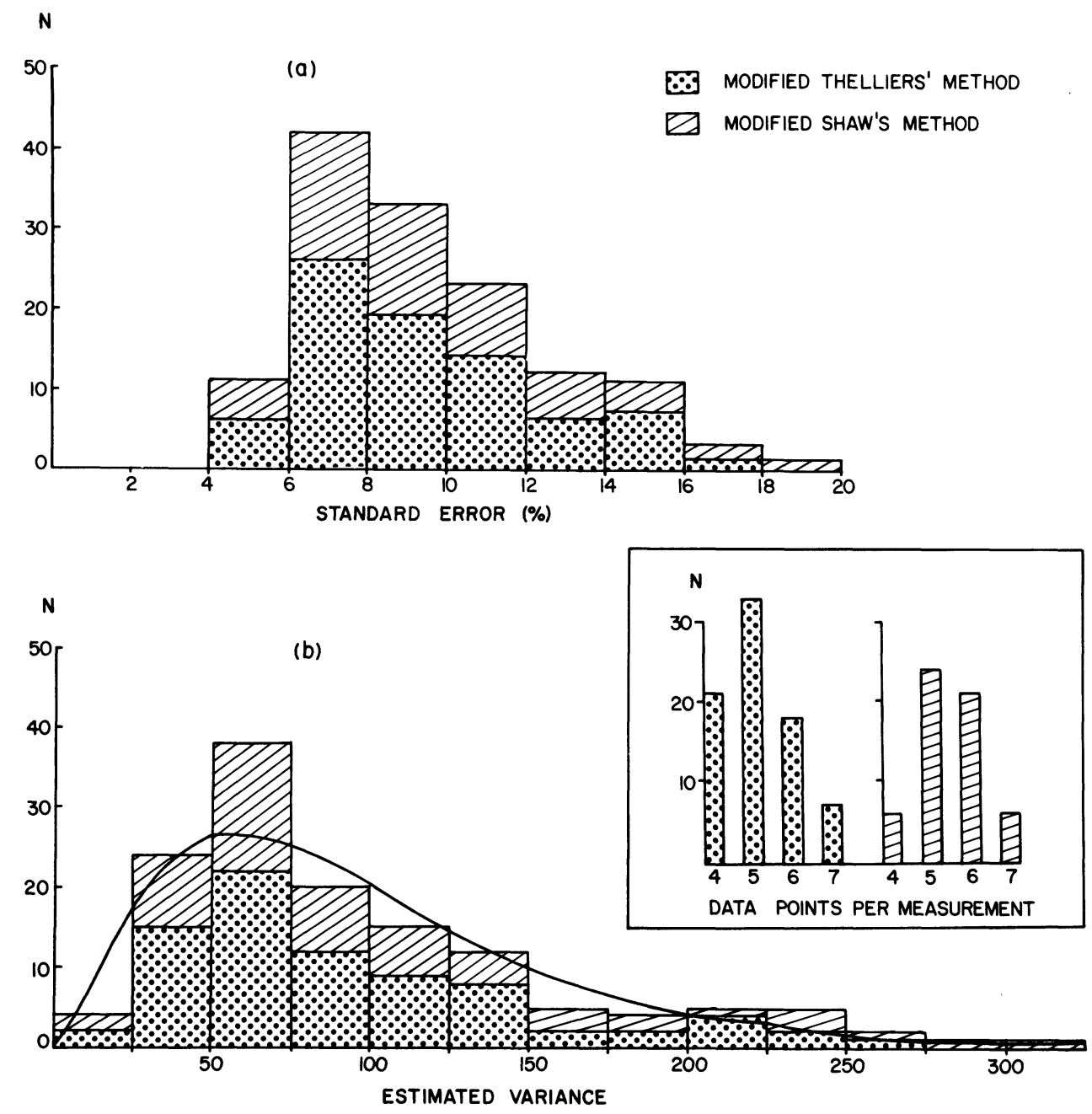

Fig. 6. (a) Histogram of standard errors determined for the 136 individual palaeointensity measurements. (b) Histogram of the estimated variances for the 136 measurements, together with the best fit chi-square distribution ( 5 degrees of freedom). Inset-Histogram of number of data points per least-squares fit.

of equal expectation were used and the observed value of the test statistic, $\chi^{2}$, was 5.74. A chi-square distributed varialble with 5 d.o.f. ( 8 cells less the 3 constraints) will exceed this value with probability 0.333 . Hence there is no reason to reject the hypothesis that the estimated variances from the Modified Shaw's method experiments are chi-square distributed with 4 d.o.f.

The best fit chi-square distribution to the 79 estimated variances (see Fig. 6b) from the Modified thelliers' method has 5 d.o.f. with a mean estimated variance of 93.92 (mean estimated standard deviation of $9.7 \%$ ). This increased number of d.o.f. is the manifestation of the smaller dispersion of the observed errors for the Modified Thelliers' method, 
and, as previously noted, was to be expected. In performing the chi-square goodness of fit test 10 cells of equal expectation were used and the observed value of the test statistic, $\chi^{2}$, was 10.75. A chi-square distributed variable with 7 d.o.f. (10 cells less the 3 constraints) will exceed this value with probability 0.188 . Hence there is no reason to reject the hypothesis that the estimated variances from the Modified Thelliers' method experiments are chi-square distributed with 5 d.o.f.

From the above it may be accepted that the mean estimated variance from the Modified Shaw's method experiments is chi-square distributed with 228 d.o.f. and the mean estimated variance from the Modified Thelliers' method experiments is chi-square distributed with 395 d.o.f. The ratio of these two mean estimates is 1.097 and an $F$ distributed variable with 228 and 395 d.o.f. will exceed this value with probability 0.211 . Hence the data give no reason to reject the hypothesis that the percentage standard deviation of the random experimental errors for the Modified Shaw's method is the same as for the Modified Thelliers' method. However, the observed dispersion of the estimated errors will, in general, be slightly larger for the Modified Shaw's method than for the Modified Thelliers' method.

Since the distribution of both sets of estimated variances are acceptable chi-square, the mean estimated variances are not significantly different and the d.o.f. only differ by unity, the combined set shoult also be acceptably chi-square distributed. The best fit chisquare distribution to the combined set of 136 estimated variances has 5 d.o.f. with a mean estimated variance of 97.75 (mean estimated standard deviation of $9.9 \%$ ) and is plotted in Fig. 6b for comparison with the histogram of the combined data set. In performing the chi-square goodness of fit test 20 cells of equal expectation were used and the observed value of the test statistic, $\chi^{2}$, was 14.88 . A chi-square distributed variable with 17 d.o.f. ( 20 cells less the 3 constraints) will exceed this value with probability 0.604 . Hence it may be accepted that the combined set of estimated variances is chi-square distributed with 5 d.o.f. and so the mean estimated variance from the combined set of data is chi-square distributed with 680 d.o.f.

\subsection{Comparison of within-sample and within-specimen results}

The mean estimated standard deviation of a single measurement, by either method, is $9.9 \%$ and it is useful to identify the sources of this error. In both methods the spectrum is, effectively, divided into segments and a palaeointensity determination performed on each segment. Those segments which provide consistent results are then plotted and an overall result for the specimen is determined from a least-squares linear regression. Each point will have an error caused by the experimental error in determination of the ancient field recorded by that blocking temperature segment and any random error in the actual recording process of that segment. Hence the overall standard deviation of $9.9 \%$ reflects the experimental error in measurement plus the dispersion caused by internal (i.e. withinspecimen) rock magnetic recording errors.

Consider two palaeointensity determinations $F_{1 i}$ and $F_{2 i}$ obtained from two specimens within the same sample. From the above analysis of random errors it follows that

$$
F_{j i} \sim N\left(\mu_{j i}, c^{2} \mu_{j i}^{2}\right) ; \quad j=1,2 .
$$


where the symbol " " is to be read as "is distributed as" and $N(a, b)$ is the normal distribution with mean value $a$ and variance $b$. Here $\mu_{j i}$ is the actual recorded palaeointensity in specimen $j$ from sample $i$ and $c$ is the percentage standard deviation of the measurement error. If specimens within a sample give consistent result then $\mu_{1 i}=\mu_{2 i}=$ $\mu_{i}$ and it follows from Eq. (4) that

$$
1 / 2 \Delta_{i}^{2} \sim c^{2} \chi_{1}^{2}
$$

where

$$
\Delta_{i}=\frac{F_{1 i}-F_{2 i}}{\mu_{i}}
$$

and $\chi_{n}{ }^{2}$ is the chi-square distribution with $n$ d.o.f. Taking $N$ values of $\Delta_{i}$ from independent pairs of specimens, each pair from the same sample (the samples need not be from the same site), it then follows that

$$
S^{2}=\frac{\sum_{i=1}^{N} \Delta_{i}{ }^{2}}{2 N} \sim \frac{c^{2} \chi_{N}{ }^{2}}{N}
$$

and so $S^{2}$ is an unbiased estimator for $c^{2}$. Evidently the $\mu_{i}$ values are not known but if $\bar{x}_{i}=1 / 2\left(x_{1 i}+x_{2 i}\right)$ is used instead the effect on the $\Delta_{i}$ values is very small and may be ignored.

Taking the 21 samples for which two results have been obtained using the Modified Thelliers' method, $S^{2}=0.001906$ (i.e. a standard deviation of $4.4 \%$ ) with 21 d.o.f. similarly the 11 samples for which two results have been obtained using the Modified Shaw's method give $S^{2}=0.002937$ (i.e. a standard deviation of $5.4 \%$ ) with 11 d.o.f. From the $F$-distribution it follows that there is no reason to reject the hypothesis that the withinsample repeatability of the Modified Shaw's method is the same as the within-sample repeatability of the Modified Thelliers' method. However, the within-sample variance of either method is significantly less than the variance assigned to a single measurement (i.e. standard deviation of $9.9 \%$ ). Thus it may be concluded that specimens within a sample give very consistent results when palaeointensities are determined by the same method. Furthermore, this implies that random errors of the actual recording process within the spectrum segments are reproduced in specimens from the same sample and that the dispersion caused by these within-specimen rock magnetic recording errors constitute the major portion of the overall error assigned to a single measurement. Consequently it may be deduced that little further information is gained by performing repeated measurements of the same method on specimens from a single sample; this merely averages out the experimental error-which constitutes only a minor portion of the overall error.

\subsection{Statistical comparison between results from the Thelliers' and Shaw's method}

If $F_{1 i}$ of Eq(4) refers to a measurement from sample $i$ using the Modified Shaw's method and $F_{2 i}$ refers to a measurement from the same sample using the Modified Thelliers' method then, under the null hypothesis that there is no systematic difference between the result from the two methods, i.e. $\mu_{1 i}=\mu_{2 i}=\mu$, follows that the $\Delta_{i}$, values will 
be normally distributed with mean zero. Hence if there are $n$ samples for which a single result has been obtained from each method

$$
T=\frac{\bar{\Delta} \sqrt{N}}{S} \sim t[N-1]
$$

where

$$
\begin{aligned}
\bar{\Delta} & =\frac{1}{N} \sum_{i=1}^{N} \Delta_{i}, \\
S_{\Delta} & =\sum_{i=1}^{N}\left(\Delta_{i}-\bar{\Delta}\right)^{2} /(N-1)
\end{aligned}
$$

and $t[N-1]$ is the Student's- $t$ distribution with $(N-1)$ d.o.f. There are 27 such samples reported here and initially it may be noted that of these the Modified Shaw's method gave the higher result in 15 cases, showing immediately that there is no large scale systematic difference. Substituting the observed values from the 27 samples into Eq. (8) gives $T=$ -0.0136 with 26 d.o.f. On a two-tailed test this value of $t$ will be exceeded on $98.9 \%$ of occasions. Hence there is no significant systematic difference between the results from the Modified Shaw's method and the Modified Thelliers' method. Substituting these same values into Eq. (7) gives $S^{2}=0.007526$ (i.e. a standard deviation of $8.7 \%$ ) with 27 d.o.f. This estimated variance, although slightly smaller than the overall variance assigned to a single observation (i.e. standard deviation of $9.9 \%$ ), is not significantly different from it. Thus it appears that the random within-specimen rock magnetic errors show up when making replicate measurements using the two different methods.

Equation (7) can again be used to determine whether different samples from the same site give consistent results, the subscripts 1 and 2 now referring to single observations from different samples within the same site and the site may vary with the subscript $i$. There are 13 such independent pairs where both observations have been made using the Modified Thelliers' method and these give $S^{2}=0.014870$ (i.e. a standard deviation of $12.2 \%$ ) with 13 d.o.f. Similarly there are 15 such independent pairs where both observations have been made using the Modified Shaw's method and these give $S^{2}=0.009156$ (i.e. a standard deviation of $9.6 \%$ ) with 15 d.o.f. Finally, there are 20 such independent pairs with a result from each of the methods and these give $S^{2}=0.012640$ (i.e. a standard deviation of $11.2 \%$ ) with 20 d.o.f. These estimated variances are not significantly different from each other and neither are any of them significantly different from the overall variance assigned to a single measurement. Hence the data give no reason to reject the hypothesis that the between-sample (or within-site) variance is zero, independent of the palaeointensity determination method used. This is equivalent to stating that the dispersion of observations from different samples within a site is adequately represented by the dispersion of observations from different spectrum segments within a sample. Thus the value of $10 \%$ for the standard deviation of errors in a palaeointensity determination is a realistic realization of all the errors involved.

If the least oxidize samples were studied, then clearly it is very unlikely a reliable result would be obrained either by Shaw's method or its modified version. Thus the 
foregoing comparison of the Modified Thelliers' and Modified Shaw's methods, and the determination of within-sample and within-site consistency of results, relate specifically to samples chosen by our preselection procedure.

\section{Conclusions}

The standard errors determined from the experimental data for each specimen are typically $10 \%$, irrespective of the method used for the palaeointensity determination. This error is made up of the experimental error in measurement plus dispersion caused by rock magnetic recording errors, the latter being the major component of the error. For both the Thelliers' and Shaw's methods the within-sample repeatability is consistent with standard errors of only $5 \%$, whereas the between sample-values within a site again suggest standard errors of $10 \%$. This indicates that the rock magnetic errors have little random variation throughout a sample, each specimen within the sample merely reproducing the errors. However, between samples the rock magnetic errors appear to be random. Thus, apart from providing a check on gross systematic errors in measurement, little is to be gained by making repeat measurements on specimens from the same sample.

It was noted that for theoretical reasons (associated solely with the manner in which the data are analysed) we expected the dispersion of observed errors for the Modified Shaw's method to be slightly greater than for the Modified Thelliers' method. Experimentally we found this to be so. However, apart from this minor difference in the distributions of the random errors we were unable to show the existence of any differences between the results from the Shaw's method and the Thelliers' method. Hence we conclude that the Shaw's method provides a reliable alternative to the Thelliers' method.

We do, however, stress that all the above conclusions refer to specimens which have been preselected according to their low temperature susceptibility behaviour. It is unlikely that these conclusions will hold for specimens which have not been preselected in this manner.

\section{REFERENCES}

AzIZ-UR-Rahmam, Palaeomagnetic secular variation for Recent normal and reversed epochs, from the Newer Volcanics of Victoria, Australia, Geophys. J. R. Astron. Soc., 24, 255-269, 1971.

Aziz-UR-Rahman and I. MCDougall, Palaeomagnetism and palaeosecular variation on lavas from Norfolk and Philip Islands, southwest Pacific Ocean, Geophys. J. R. Astron. Soc., 33, 141-155, 1973.

Chamalaun, F. H., Paleomagnetism of Reunion Island and its bearing on secular variation, J. Geophys. Res., 73, 4647-4559, 1968

ChAmpion, D. E., Holocene geomagnetic secular variation in the Western United States: implications for the global geomagnetic field, U.S. Geol. Surv. Open File Rep., No. 80-824, 314 pp., 1980.

COE, R. S., Paleointensity of the earth's magnetic field determined from Tertiary and Quaternary rocks, $J$. Geophys. Res., 72, 3247-3262, 1967.

CoE, R. S. and C. S. Gromme, A comparison of three methods of determining geomagnetic palaeointensities, $J$. Geomag. Geoelectr., 25, 415-435, 1973.

Coe, R. S., C. S. Gromme and E. A. Mankinen, Geomagnetic paleointensities from radiocarbon-dated flows on the Hawaii and the question of the Pacific nondipole low, J. Geophys. Res., 83, 1740-1755, 1978.

Cox, A., The frequency of geomagnetic reversals and the symmetry of the non-dipole field, Rev. Geophys. Space Phys., 13, 35-49, 1975. 
Duncan, R. A., Palaeosecular variation at the Society Islands, French Polynesia, Geophys. J. R. Astron. Soc., 41, 245-254, 1975.

Irving, E., Paleomagnetism and its Application to Geological and Geophysical Problems, 399 pp., Wiley Interscience, New York, 1964.

Kono, M., Reliability of palaeointensity methods using alternating field demagnetization and anhysteretic remanence, Geophys. J. R. Astron. Soc., 54, 241-261, 1978.

McDougall, I. and F. H. Chamalaun, Isotopic dating and geomagnetic polarity studies on volcanic rocks from Mauritius, Indian Ocean, Geol. Soc. Am. Bull., 80, 1419-1442, 1969.

McElhinny, M. W., Palaeomagnetism and Plate Tectonics, 358 pp., Cambridge Univ. Press, London, 1973.

Merrill, R. T. and M. W. McElhinny, Anomalies in the time-averaged paleomagnetic field and their implications for the lower mantle, Rev. Geophys. Space Phys., 15, 309-321, 1977.

PAtton, B. J. and J. L. Fitch, Anhysteretic remanent magnetization in small steady fields, J. Geophys. Res., 67, 307-311, 1962.

Senanayake, W. E. and M. W. McElhinny, Hysteresis and susceptibility characteristics of magnetite and titanomagnetites: interpretation of results from basaltic rocks, Phys. Earth Planet. Inter., 26, 47-55, 1981.

SHAw, J., A new method of determining the magnitude of the palaeomagnetic field, Geophys. J. R. Astron. Soc., 39, 133-141, 1974.

Smith, P. J., The intensity of the Tertiary geomagnetic field, Geophys. J. R. Astron. Soc., 12, 239-258, 1967.

Thellier, E. and O. Thellier, Sur l'intensité du champ magnetique terrestre dans le passé historique et geologique, Ann. Geophys., 15, 285-367, 1959.

Watkins, N. D., L. Kristjansson, and I. MCDougall, A detailed palaeomagnetic survey of the type location for the Gilsa geomagnetic polarity event, Earth Planet. Sci. Lett., 27, 436-444, 1975.

Watkins, N. D., I. McDougall, and L. Kristjansson, Upper Miocene and Pliocene geomagnetic secular variation in the Borgarfjordur area of Western Iceland, Geophys. J. R. Astron. Soc., 49, 609-632, 1977.

WiLSON, R. L., Permanent aspects of the earth's non-dipole magnetic field over upper Teriary times, Geophys. J. R. Astron. Soc., 19, 417-437, 1970.

WiLson, R. L., Dipole offset: The time averaged palaeomagnetic field over the past 25 million years, Geophys. J. R. Astron. Soc., 22, 491-504, 1971.

Wilson, R. L., Palaeomagnetic differences between normal and reversed field sources, and the problem of farsided and right-handed pole positions, Geophys. J. R. Astron. Soc., 28, 295-304, 1972.

Wilson, R. L. and M. W. McElhinnY, Investigation of the large scale palaeomagnetic field over the past 25 million years: Eastward shift of the Icelandic spreading ridge, Geophys. J. R. Astron. Soc., 39, 571-586, 1974. 